Titre : Leçons à tirer du refus de l'inoculation variolique : Premiers débats entre scientifiques et évolution de la tendance au refus de la vaccination

Auteur : Réal Roy

Publication : La santé publique à une ère marquée par le doute - Origines religieuses et culturelles de l'hésitation des Canadiens face à la vaccination

Directeurs : Paul Bramadat, Maryse Guay, Julie A. Bettinger et Réal Roy

Pages : $100-115$

ISBN : 978-2-7622-0359-2

URI : http://hdl.handle.net/11143/16029

DOI : https://doi.org/10.17118/11143/16029

Éditeur : Les Éditions de l'Université de Sherbrooke (ÉDUS) 


\title{
Leçons à tirer du refus de l'inoculation variolique : Premiers débats entre scientifiques et évolution de la tendance au refus de la vaccination
}

\author{
RÉAL ROY
}

Introduction

L'éradication de la variole, en 1980, fut l'aboutissement d'une campagne internationale intensive de vaccination lancée en 1967 par l'Organisation mondiale de la Santé (OMS). Ce succès est encore, pour les promoteurs de la vaccination, une preuve des plus évidentes de son pouvoir de prévention des maladies infectieuses (Khan et Smith. 2010). Au Canada' et aux États-Unis, un exemple de réussite semblable s'est produit quand, à la suite de l'apparition de vaccins, le nombre de cas de poliomyélite, de rougeole, d'oreillons et de rubéole s'est mis à décliner rapidement.

Toutefois, malgré ces données impressionnantes qui vont à l'appui de l'efficacité des campagnes de vaccination, on constate la montée d'une tendance mondiale favorisant la réticence à la vaccination. Aux États-Unis, par exemple, pour les enfants entrant à l'école, le taux des exemptions pour des raisons autres que des causes médicales a augmenté de 0,98 à 1,48 p. cent entre 1991 et 2004, les motivations philosophiques et personnelles ayant pris une place plus grande que les motivations religieuses (Omer et coll., 2006) ${ }^{2}$. Le taux d'exemption pourrait même être de beaucoup supérieur à 1,5 p. cent, puisque les gens de même culture habitent dans la même collectivité et partagent souvent des espaces collectifs tels que les églises et les lieux de recueillement. Dans l'État du Washington, par exemple, le taux d'exemption moyen était de 7,4 p. cent, mais, dans certains comtés, il atteignait 26 p. cent (Omer

1. Pour mieux connaître la question de la vaccination et des maladies pouvant être prévenues par un vaccin, se reporter au chapitre 8 du présent ouvrage, rédigé par Bettinger et MacDonald.

2. Nous utilisons les données américaines parce que la vaccination n'est généralement pas obligatoire au Canada et que les données sur la réticence peuvent varier d'une province à l'autre. 
et coll., 2009). Au Canada, on retrouve aussi des grappes de communautés non immunisées, mais le phénomène n'est en général pas documenté. Les conséquences immédiates d'un tel refus ne sont sans doute pas considérables, mais, s'il annonce une tendance (voir le chapitre 7 de Guay, Dubé et Laberge dans le présent ouvrage), comme il semble le faire depuis vingt ans, on pourrait prévoir des éclosions de maladies infectieuses autrefois contrôlées, dont les conséquences seraient graves, puisqu'elles comprendraient l'invalidité à long terme, voire la mort.

Prenons l'exemple de l'éclosion de rubéole survenue en Ontario en 2005; la maladie est apparue dans une école chrétienne où jusqu'à 60 p. cent des élèves n'étaient pas vaccinés, puisqu'ilsappartenaienten majoritéà un groupe particulier défendant des doctrines religieuses inspirées de l'Église réformée néerlandaise. Dans cette collectivité, on croit généralement que l'homme ne doit pas nuire au plan divin touchant son corps (Basrur, 2005; Sibbald, 2005).

Comme l'ont démontré d'autres auteurs participant à cet ouvrage, un tel refus est aujourd'hui assimilé à une mentalité antiscientifique. En réalité, le refus de la vaccination n'est pas un phénomène nouveau et il n'est pas toujours motivé par un rejet de la science. Ses origines remontent en fait jusqu'à la préhistoire de la vaccination, c'est-à-dire au développement de la procédure d'inoculation antivariolique que l'on appelait la variolation, en Europe, au XVIIIe siècle?

Mon objectif, dans ce chapitre, est de brosser un portrait historique et scientifique du phénomène de refus de la vaccination et des débats scientifiques qui entourent l'origine et l'évolution des concepts et techniques associés à la vaccination ${ }^{4}$. J'ai notamment l'intention de démontrer que les scientifiques ont toujours eu un rôle complexe à jouer dans ces discussions, que ce soit au début de l'inoculation et de la vaccination antivariolique ou, plus tard, dans la mise au point de vaccins contre d'autres maladies. Je traiterai d'abord de l'inoculation, c'est-à-dire de cette procédure qui consiste à transmettre la variole humaine d'une personne malade à des individus en santé; je me pencherai ensuite sur la vaccination antivariolique, qui représente la transmission à des humains en santé du virus de la vaccine (ou variole de la vache) plutôt que de la variole humaine. En revenant ainsi aux débuts de l'histoire de la vaccination, nous pourrons nous rappeler que la réticence à la vaccination observée présentement au Canada (Guay et coll., 2015) reste un problème à vaincre dans la population en général, même si les progrès de la microbiologie ont développé notre connaissance commune de l'immunité humaine, de la nature des maladies microbiennes et de leur application dans la vaccination bien au-delà de ce qu'ont appris Jenner et Pasteur.

3. Dans le présent chapitre, l'expression « inoculation variolique » (ou variolation) désigne la transmission de la variole humaine (virus de la variola) d'une personne malade à une personne en bonne santé. L'expression "vaccination antivariolique » renvoie à la transmission de la vaccine (ou vaccinia). En son temps, Jenner utilisait le terme vaccinia, dérivé de vacca (ou vache) en latin; cette maladie propre à la vache ne produisait que de légers symptômes chez l'humain. Par conséquent, l'expression « vaccination antivariolique » renvoie à la transmission à un être humain en bonne santé d'un virus différent qui cause une maladie chez la vache. On pensait, à l'époque de Jenner et jusqu'au début du XXe siècle, que la vaccinia et la vaccine étaient semblables. On sait aujourd'hui, grâce à l'analyse moléculaire du vaccin, que les virus de la vaccinia et de la vaccine sont différents. On ne connaît pas l'hôte naturel de la vaccinia. La vache, cependant, demeure l'hôte naturel de la vaccine. Baxby (1981) a élaboré différentes hypothèses sur l'origine de la vaccinia.

4. Un autre chapitre du présent ouvrage examine plus exhaustivement certains facteurs déterminants de l'opposition à la vaccination au Canada, pour trois types de vaccin (variole, diphtérie et poliomyélite). 


\section{La variolation ou l'inoculation de la variole en Chine et en Europe (1721-1798)}

Avec la vaccination sont nées les objections liées à cette procédure. En 1798, Edward Jenner (1749-1823) ${ }^{5}$ publiait un résumé de ses expériences et démontrait que la vaccination contre le virus de la vaccine protégerait contre la variole humaine, ce dont nous discuterons dans la section suivante. Selon Pasteur, il faut voir là le fondement scientifique de la vaccination. Avant d'étudier les expériences de Jenner, toutefois, il est essentiel de discuter ici d'une technique appelée variolation ou inoculation de la variole, telle qu'elle était pratiquée en Europe à la même époque.

Avant les expériences de vaccination de Jenner, les médecins protégeaient les individus en santé de la variole en leur inoculant le virus de la maladie elle-même, prélevé sur les pustules de malades infectés, mais en voie de guérison. Les premières inoculations contrôlées de la variole ont eu lieu en Chine. Needham, Gweidjen et Sivin (2000), après des recherches soutenues dans la documentation historique traitant de ce sujet, ont conclu que la mention la plus ancienne de cette méthode fut décrite par le pédiatre de la Dynastie Ming, Wan Quan, en 1549, dans un ouvrage intitulé Heart Method for Smallpox - Douzhen xinfa (Méthode de prévention pour la petite vérole). La première mention écrite de l'inoculation de la variole figure dans un traité médical de 1695, écrit par un médecin célèbre de l'époque, Zhang Lu (1617-1700). Il en décrit trois méthodes différentes : 1) insertion d'un chiffon de coton imprégné de pus de variole dans une narine d'un enfant en santé; 2) utilisation de squames qui sont des fragments de peau ressemblant à des écailles prélevés sur le site de l'infection; 3) obligation, pour l'enfant en santé, de porter des vêtements d'un autre enfant ayant contracté la maladie. Au cours du XVIII siècle, les techniques chinoises se sont graduellement raffinées. Un ouvrage rédigé en 1713 montre une quatrième méthode, dans laquelle on introduit des squames en poudre dans une narine, à l'aide d'un mince tube d'argent. À la fin de ce siècle, en matière de variolation ou d'inoculation variolique, deux écoles s'étaient formées : celle de Huzhou, qui préférait utiliser du pus fraîchement prélevé, et celle de Songjiang, qui utilisait des squames plus âgées et traitées médicalement, que l'on appelait de la «variole cuite » (Leung, 2011).

En Europe, l'inoculation apparut en 1721, en Angleterre, et son promoteur était Lady Montagu; à Athènes et à Venise, cependant, Timoni et Pylarini firent connaître la procédure, respectivement en 1714 et 1716 (Baxby, 1981). Se trouvant à Constantinople, Lady Montagu vit une technique utilisée par des femmes originaires du Caucase, qui faisaient des incisions dans les pustules de personnes infectées et en tiraient des inoculums du virus qu'elles transféraient par incision dans le bras d'individus en santé désireux de se protéger de la maladie. Le récepteur la contractait, mais on disait alors qu'elle était moins virulente que la « vraie » variole. Cette allégation n'a jamais été validée ${ }^{6}$. Malgré l'absence de données initiales, Lady Montagu fut si impressionnée par cette technique qu'elle demanda à un médecin de l'exécuter sur l'un de ses enfants, à son retour en Angleterre en 1721; le succès remporté la convainquit des bienfaits de cette procédure. Celle-ci fit l'objet de nombreuses objections dès son introduction, mais

5. Edward Jenner, médecin britannique, fut le premier à démontrer au moyen d'expériences qu'une maladie des animaux (vaccine) pouvait, lorsque injectée dans un être humain, le protéger de maladies propres à l'homme (variole).

6. James Jurin (1684-1750) a commencé à recueillir des données sur la variolation après les années 1722-1723. 
elle devint immédiatement célèbre grâce à l'appui de James Jurin (1684-1750), scientifique et médecin distingué.

Ce dernier, grand partisan des innovations du physicien Newton, avait fait des études de médecine et s'était intéressé à la nouvelle technique d'inoculation. Il fut le premier à dresser un répertoire systématique de données sur les décès attribuables à des épidémies de variole et aux inoculations de ce virus (Diderot et d'Alembert, 1778). Avec ses associés, il voulait amasser des preuves à l'appui de la technique novatrice, afin de répondre aux médecins et profanes qui doutaient que l'on puisse se protéger d'une maladie en la contractant d'abord. Jurin avait compris que le meilleur moyen de convaincre les gens des bienfaits de l'inoculation était de leur montrer clairement le plus faible nombre de décès attribuables à la variole artificielle (inoculée), par rapport à la variole naturelle. Il supposait que de telles données inciteraient les médecins, les politiciens et le public à promouvoir l'expansion de la technique. La participation des hôpitaux dédiés au traitement de la maladie facilita la collecte des données. L'hôpital de St. Pancras, fondé à Londres en 1746, traitait des patients atteints de la variole naturelle, mais faisait également des inoculations sur des individus en santé. Suivant la méthode de Jurin, l'hôpital dressa des dossiers précis sur les succès ou les échecs du traitement, en distinguant les patients ayant contracté la variole naturelle de ceux qui avaient été inoculés. Ces données se sont trouvées au centre de la controverse entourant les bienfaits et l'innocuité de l'inoculation et ont constitué la base d'un long essai rédigé par d'Alembert (1713-1787)', qui plaidait en faveur de cette méthode (d'Alembert, [1821], 1967).

La méthode de l'inoculation préconisée par Jurin reçut un appui inattendu dans une lettre du père François d'Entrecolles (1664-1741) ${ }^{8}$, envoyée en 1726 de Beijing, en Chine, où était décrite la méthode chinoise d'inoculation variolique (Vissière et Vissière, 1979). Ce document avait été écrit en réponse à une lettre publiée en 1724 dans le journal des Jésuites intitulé Mémoires de Trévoux ${ }^{9}$, où l'on décrivait la procédure d'inoculation récemment introduite en Europe. Le père d'Entrecolles expliquait la méthode connue sous le nom de zhongdou' en faisant référence à trois rapports écrits de médecins pratiquant dans la Cité interdite de Beijing. La lettre démontrait que les médecins chinois connaissaient depuis le début du XVIIIe siècle les variations entre les différents virus de la variole, certains étant plus virulents que d'autres. La distinction provenait du temps nécessaire au développement des pustules cutanées. Le philosophe français Voltaire" cita aussitôt cette lettre dans sa onzième Lettre philosophique, dans le but de prouver que l'inoculation, récemment arrivée en Europe, était pratiquée en Chine depuis un siècle. Ajoutons que cette lettre était brièvement citée dans un long article de l'Encyclopédie de Diderot et d'Alembert (1778). La longueur de l'article dénote l'importance de

7. Jean Le Rond d'Alembert, mathématicien et philosophe français, fut corédacteur, avec Denis Diderot, de la première encyclopédie générale de ce pays.

8. François d'Entrecolles était un Jésuite qui s'est installé en Chine en 1698 et a rédigé une ample correspondance sur différents aspects de la vie dans ce pays, notamment sur la porcelaine (l'une de ses lettres les plus célèbres, écrite en 1707) et sur l'infanticide (datant de 1720).

9. Les Mémoires de Trévoux, publiés entre 1701 et 1762 par les Jésuites du collège Louis-le-Grand, ont joué un rôle important, car ils contenaient des articles variés sur l'histoire, la littérature et les sciences naturelles, allant bien audelà de la théologie et de la spiritualité. Pour en savoir plus, se reporter à Taurand (1993).

10. Ces rapports laissent entrevoir que les praticiens chinois avaient saisi le concept de l'atténuation et exposé le matériel infecté à de hautes températures pour réduire la pathogénicité des inoculums à utiliser sur les humains (Needham et coll., 2000). Plus de cent ans après, Pasteur repris ces méthodes d'atténuation dans la conception de vaccins.

11. Il s'agit du nom de plume de François-Marie Arouet (1694-1778), écrivain, historien et philosophe français célèbre pour sa critique de l'Église catholique et son amour de la Chine. 
la controverse au sujet de l'inoculation de la variole, à cette époque de l'histoire médicale. Ce débat fut sans doute l'élément fondamental de la nouvelle méthode scientifique appliquée à la médecine et promue pendant le siècle des Lumières.

\title{
Appuis et objections à l'inoculation variolique pendant le siècle des Lumières
}

\begin{abstract}
Avant la publication de l'Encyclopédie, d'Alembert avait fait part de sa réflexion sur l'inoculation à l'Académie royale des sciences de Paris, en 1760 (d'Alembert [1821], 1967). Passant en revue, avec grande précision, les arguments en faveur de l'inoculation, il avait soulevé des inquiétudes pouvant s'apparenter aux allégations des groupes actuellement réticents à la vaccination. Cette présentation, jointe à l'article paru en 1778 dans l'Encyclopédie, résumait très bien les antécédents de la nouvelle technique médicale. L'article contenait également une liste des douze principales objections à l'inoculation variolique circulant à cette époque en Europe, ainsi qu'une réfutation pour chacune d'entre elles. Les objections sont reproduites ci-dessous; réparties entre celles qui sont d'ordre physique et celles qui sont d'ordre moral, elles donnent une bonne idée des débats qu'a suscités l'inoculation, comme précurseur de la vaccination, durant une bonne partie du XVIII siècle.
\end{abstract}

1. La maladie transmise par l'inoculation n'est pas la variole. L'Encyclopédie fait la distinction entre la variole artificielle et la variole naturelle, mais l'article note que l'inoculation a engendré une maladie identique à la variole naturelle.

2. La variole inoculée est plus dangereuse que la variole naturelle. Les travaux épidémiologiques de Jurin sur la variole et l'inoculation, les premiers en leur genre, avaient pour but de démontrer que l'inoculation était moins dangereuse que la variole naturelle. Dans l'article de l'Encyclopédie, la réfutation était principalement basée sur les données recueillies entre 1745 et 1763 à l'hôpital londonien traitant la variole; elles montraient clairement que les taux de décès suivant l'inoculation étaient inférieurs à ceux suivant une infection à la variole naturelle ${ }^{12}$.

3. L'inoculation ne prévient pas la récurrence de la variole. Pour réfuter cette objection, on n'a qu'à compter le nombre de personnes qui n'ont jamais été réinfectées par la variole après une inoculation. La durabilité de l'immunité était un concept élémentaire important lorsque faisait rage la controverse sur la variole, mais ce n'était pas une idée nouvelle ${ }^{13}$.

4. L'inoculum pouvait transmettre d'autres maladies (comme le typhus). Bien que l'Encyclopédie réfute également cette objection, nous savons aujourd'hui qu'elle était véridique, à la suite de l'apparition, au début du XXe siècle, de nouvelles données au sujet de la transmission de la Salmonella quand la vaccination antivariolique n'était pas faite selon une méthode aseptique ${ }^{14}$. II est donc tout à fait probable que l'inoculation ait pu causer d'autres maladies, en plus de la variole.

5. L'inoculation laisse des blessures et peut entraîner des tumeurs. Selon l'article de l'Encyclopédie, aucune donnée ne démontrait que l'inoculation variolique causait des blessures et des tumeurs chez les patients. Les auteurs affirmaient que, si l'inoculation causait de tels accidents, ils étaient bien moins graves que les blessures entraînées par la variole naturelle.

12. Des 6456 patients atteints de variole naturelle, 1634 en décédèrent (soit 25,3 p. cent ou 1 sur 4), contre seulement 10 des 3434 patients ayant reçu une inoculation variolique (soit 0,2 p. cent ou 1 sur 340) et traités au cours d'une période de 18 ans (de 1745 à 1763). Ces données sont disponibles dans d'Alembert ([1821], 1967).

13. Étudiant l'épidémie de peste ayant eu lieu à Athènes, Thucydide (c. 460 à c. 400 BC) a proposé dans son Histoire de la guerre du Péloponnèse (Thucydide, 1928) qu'on pouvait acquérir une protection contre la maladie : « ...C'était ceux qui avaient échappé à la maladie qui se montraient les plus compatissants pour les mourants et les malades, car connaissant déjà le mal, ils étaient en sécurité. » (V. livre II, LI, 351)

14. Aujourd'hui, certains vaccins contiennent encore une petite quantité d'un antibiotique afin de prévenir la croissance des bactéries pathogènes dans la préparation; c'est ainsi que l'on retrouve de la néomycine dans le vaccin RRO (rougeole, rubéole, oreillons). 
6. L'inoculation est contre nature. Pour réfuter cette objection, on a affirmé que l'inoculation était moins douloureuse qu'une saignée, qui était alors considérée comme une méthode « naturelle » de guérison.

Outre ces six objections, il s'en trouvait six autres que l'on considérait alors comme étant d'ordre moral plutôt que physique. Ce sont les suivantes:

7. L'inoculation usurpe le droit de Dieu d'infliger la maladie ou de la prévenir.

8. Il est interdit de transmettre une terrible maladie à quelqu'un qui pourrait bien ne jamais la contracter.

9. Si un enfant meurt à la suite d'une inoculation, on l'empêche de devenir adulte et de contribuer au développement de la société.

10. L'inoculation variolique augmente la présence de la variole naturelle'15.

11. Il est interdit de causer un léger tort pour le bien du plus grand nombre.

12. L'inoculation est un tort moral, car elle a causé des décès.

Dans l'Encyclopédie, la septième objection est réfutée par la simple affirmation que Dieu nous a également donné la raison et, par conséquent, la capacité de survivre aux problèmes causés par la maladie et les autres formes de la malchance. II n'en reste pas moins que, comme Bramadat (au premier chapitre) et d'autres auteurs du présent ouvrage, cette objection s'entend encore aujourd'hui : durant l'éclosion de rubéole à Woodstock (Ontario) ${ }^{16}$, en 2005, les fidèles de l'Église réformée des Pays-Bas l'ont revendiquée pour expliquer leur refus de faire vacciner leurs enfants.

Les défenseurs de l'inoculation ont réfuté la huitième objection en s'appuyant sur une analyse des risques et des bienfaits. Comme le risque de décès à la suite d'une inoculation est moins élevé que celui qui suit une infection naturelle, ils estimaient que, dans une perspective sociale, l'inoculation assurait la survie d'un plus grand nombre de personnes aptes à contribuer au développement de la société.

Une autre objection morale répandue au XVIII siècle reposait sur le fait qu'on ne pouvait permettre de nuire à quelques-uns pour avantager le plus grand nombre. Les défenseurs de l'inoculation associaient cette objection aux mesures prises pour prévenir la propagation de l'incendie (c'est-à-dire la destruction d'une partie d'une forêt ou d'un village pour priver le feu de matières combustibles); dans ce cas, quelques personnes subissaient des dommages, mais le reste de la population était protégé de l'incendie.

La dernière objection des opposants à l'inoculation portait sur le tort moral découlant du décès de quelques personnes s'étant soumises à la procédure. Comme celle-ci n'était pas parfaite à cette époque, certains critiques ont affirmé qu'il n'était pas moralement acceptable de risquer la vie d'une personne en santé en lui administrant une inoculation quand il est interdit de disposer de sa propre vie. On a réfuté cette objection en alléguant que d'autres procédures médicales acceptées, comme la saignée, comportaient aussi des risques.

15. Pour le lecteur d'aujourd'hui, cette objection relèverait plus de la catégorie des objections physiques que de celle des objections morales. Au XVIII e siècle, l'inoculation de la variole artificielle se faisait par la volonté de l'homme et non celle de Dieu. C'est en ce sens que de nombreuses personnes considéraient comme contraire à la morale que l'homme propage lui-même la variole en plus de celle qui se déclarait naturellement.

16. Pour une description complète de cette éclosion, se reporter à Basrur (2005). 


\section{Edward Jenner et la variole (1798-1885)}

Ayant vécu dans la dernière décennie du XVIII siècle, le médecin Edward Jenner (1749-1823) était au courant des risques associés à l'inoculation variolique (ou variolation) (se reporter à la note 4). Il se rappelait sa frayeur quand, enfant, on lui avait inoculé la variole humaine (Barquet et Domingo, 1997). Par la suite, il s'était rendu compte que certains ag riculteurs ne contractaient jamais la maladie, même s'ils se trouvaient souvent en contact avec des membres de leur famille qui en étaient atteints. L'absence de cette infection le fascinait. Un agriculteur nommé Merret ne contracta jamais la variole humaine. Il avait dit à Jenner qu'il avait été victime de la vaccine lors d'une éclosion, en 1770, au moment où il était serviteur dans une exploitation où vivaient des vaches infectées. Par la suite, on a inoculé la variole humaine à des membres de la famille de Merret. Malgré sa proximité avec ces personnes, Merret n'a jamais contracté la maladie (Jenner, 1966, 9). Merret lui-même attribuait son immunité à la vaccine, qui l'avait de quelque façon protégé de la variole humaine. Il est bien connu que le virus de la vaccine est étroitement apparenté à celui de la variole humaine. La parenté génétique est telle que les humains infectés par la vaccine sont protégés (par immunité) contre la variole humaine.

À l'époque où Jenner a vécu, nul ne connaissait les fondements scientifiques de l'immunité, ni la nature des agents causant la variole humaine et la vaccine. Jenner a eu le génie de trouver le moyen de vérifier l'allégation de Merret et d'autres agriculteurs de sa localité grâce à une simple expérience. Les agriculteurs et Jenner avaient observé que les personnes ayant contracté la vaccine, une maladie relativement peu virulente, au contact d'une vache infectée développaient une protection naturelle à vie contre la variole. Après avoir décrit plusieurs cas de personnes ayant contracté la vaccine, mais non la variole dans des épidémies subséquentes, Jenner aborda le cas d'une jeune fille, Sarah Nelmes, qui fut infectée de la vaccine en mai 1796. En conséquence, elle développa une lésion purulente sur un bras. Le 14 mai, Jenner fit une incision sur ce bras et transféra des tissus infectés à un jeune garçon de huit ans. Cet enfant n'avait jamais auparavant contracté la variole humaine. Jenner donna à la vaccine le temps de se développer et de former une cicatrice sur le bras du garçon. Puis, pour prouver que ce dernier était maintenant protégé contre la variole humaine, Jenner lui inocula le virus de cette maladie, prélevé chez un sujet infecté; le garçon ne développa jamais la maladie ${ }^{17}$. Jenner répéta la procédure sur quelques autres personnes et conclut que la vaccine avait déclenché chez le garçon un mécanisme protecteur contre la variole humaine (Jenner, [1798] 1966). II peut sembler bizarre, aujourd'hui, que Jenner ait inoculé la variole humaine chez un jeune garçon qui avait déjà reçu le virus de la vaccine; on se rappellera cependant que l'inoculation et la variolation existaient déjà depuis soixante-dix ans avant l'expérience de Jenner (se reporter aux passages précédents sur la variolation).

La description qu'a faite Jenner de son expérience avec le virus de la vaccine prélevé chez Sarah Nelmes dans An Inquiry into the Causes and Effects of the Variolae Vaccinae (1798) constitua la base sur laquelle furent lancées des campagnes de vaccination antivariolique utilisant la même méthode. Conformément à la définition énoncée par Jenner, on appela " vaccination » la procédure de transmission délibérée de la vaccine (voir Guay et coll., 2015), afin de la distinguer de l'inoculation de la variole humaine ou variolation. Selon Jenner, un vaccin consistait à administrer le virus de la vaccine dans le bras d'un humain, afin de

17. Cette expérience serait considérée comme contraire à l'éthique aujourd'hui, mais il faut se rappeler que l'inoculation variolique était une procédure médicale acceptée en 1776. 
déclencher chez lui un mécanisme de protection contre la variole humaine. La diminution radicale du nombre de victimes et de la gravité de la maladie obtenue grâce à la vaccination antivariolique, par rapport à l'inoculation, a permis d'améliorer et de sécuriser grandement le processus d'immunisation. Grâce à Jenner, on vit aussi l'un des premiers exemples du recours à l'expérience en plus de l'observation et de la mesure (temps, taille des pustules) comme méthode scientifique appliquée en médecine ${ }^{18}$.

Même si elle était supérieure à la vaccination antivariolique, la nouvelle méthode devint rapidement controversée. Les praticiens en santé publique et les médecins en ont débattu pratiquement tout au long du XIXe siècle et même au début du suivant (Baxby, 1981; Durbach, 2005). Les objections étaient, sous bien des aspects, similaires à celles qui étaient exprimées au sujet de l'inoculation, mais au moins la vaccine n'était pas une maladie de l'homme comme la variole. II est intéressant de noter, cependant, que certains se sont basés justement sur le fait que la vaccine est une maladie des animaux pour refuser la vaccination. II se trouve en effet des gens pour qui il est contraire à la morale d'insérer de la chair animale dans le corps humain. Pour mieux les comprendre, il faut se rappeler qu'au début du XIXe siècle faisait rage une grande controverse au sujet de l'espèce humaine et que la théorie de l'évolution date de 1859, quand Charles Darwin (1809-1882) a suggéré qu'un mécanisme de sélection naturelle expliquait la transformation des espèces, dans son ouvrage intitulé L'origine des espèces (Darwin, [1859] 2006). En rétrospective, la vaccination antivariolique de Jenner était l'exemple parfait de la grande proximité entre les animaux et l'homme décrite par Darwin.

Alfred Russell Wallace (1823-1913), le célèbre codécouvreur de la sélection naturelle (avec Darwin) et un scientifique respecté (et controversé) de l'époque victorienne, estimait que la vaccination antivariolique était à la fois inutile et dangereuse (Wallace, 1898) ${ }^{19}$. Ses analyses statistiques l'ont mené à conclure que les arguments médicaux appuyant la procédure et les lois rendant la vaccination obligatoire adoptées alors par la Chambre des communes britannique partaient de faux principes. Les partisans de la vaccination en vantaient l'efficacité; selon eux, la variole était si répandue que le risque de la contracter et d'en mourir dépassait de beaucoup celui des rares complications que la vaccination pouvait entraîner. Les opposants, y compris Wallace, ont de leur côté produit des calculs de risque convaincants. Selon eux, la variole n'était pas si présente et la contracter n'était pas inévitable; la vaccination ne garantissait pas une immunité suffisante et comportait autant de risques que la maladie elle-même; il existait enfin d'autres moyens plus sûrs et plus raisonnables qu'une intervention médicale rendue obligatoire par les autorités. Les discussions au sujet des preuves appuyant la vaccination se révélèrent extrêmement complexes. Les recherches faites par Wallace au sujet de la vaccination laissaient entrevoir son approche du monde naturel et social, soit ce qu'on a appelé sa cosmologie évolutionniste. Imbriquant la sélection naturelle dans une téléologie évolutionniste à base de déisme, il considérait que différents domaines apparents distincts (évolution de l'homme, spiritualisme, réforme agraire, concepts sur l'habitat naturel de l'homme véhiculés par des médecins) étaient liés et relevaient donc de la compétence des scientifiques. Il était par conséquent opposé à tout traitement simpliste, attribuant une seule cause à des phénomènes complexes, y compris la maîtrise d'une maladie évolutive au moyen

18. Jenner n'avait jamais songé à utiliser des animaux comme modèles, ce qui constitue un autre aspect important de la recherche médicale moderne. C'est Pasteur qui a été le premier à utiliser des animaux dans la conception de vaccins (Pichot, 1999).

19. Pour une description la position de Wallace face à la vaccination, se reporter à Weber (2010) et Fichman et Keelan (2007). 
d'une seule intervention comme la vaccination. Dans The Wonderful Century, Wallace, en 1898, soutenait que les programmes de vaccination obligatoire comptaient parmi les échecs les plus flagrants du siècle. II n'acceptait pas que l'expertise médicale et notamment les données cliniques recueillies par les praticiens aient préséance sur tout, y compris la liberté. Selon lui, les personnes chargées de la vaccination étaient incapables d'évaluer cette procédure avec objectivité, car leur intérêt financier les incitait à la soutenir. II ajoutait que la spécialisation et la connaissance de la vaccination engendraient des biais systématiques qui se fondaient dans les statistiques, créant des preuves soutenant la vaccination (Fichman et Keelan, 2007). Opposé à la vaccination obligatoire, Wallace s'en remettait à la science pour proposer une approche médicale différente, mettant en vedette l'acquisition d'un comportement plus sain.

Comme Wallace connaissait l'interaction complexe entre les organismes vivants et leur environnement, il lui fut plus facile de comprendre l'importance de considérer les maladies humaines et leur traitement dans le contexte des relations entre les pathogènes humains et microbiens et leur communauté biologique. Ce point de vue s'impose de plus en plus aujourd'hui, car les données sur la génétique et la génomique moléculaire desagents infectieux tels que les virus et les bactéries montrent clairement l'interaction entre leur évolution et leur environnement, ce qui peut compliquer l'élaboration de vaccins efficaces contre certaines maladies ${ }^{20}$.

\section{Une nouvelle science faisant la promotion de la vaccination et de son développement}

Au XIXe siècle, le débat entourant la vaccination était en grande partie attribuable à un manque de compréhension des agents de maladies infectieuses et de la nature de la réponse immunitaire qu'ils suscitaient chez l'hôte humain. L'absence de ces connaissances a eu pour effet de retarder la mise au point de critères de mesure du risque dans la vaccination. Pour terminer ce chapitre, nous décrirons brièvement comment la microbiologie, discipline scientifique clé permettant de créer des vaccins sûrs et à risque réduit, est née des travaux de Pasteur, Koch, Metchnikoff, Beijerinck et les autres pionniers de la microbiologie. Une bonne partie de la recherche en microbiologie, dans le domaine de la vaccination, est le résultat des interrogations suscitées auparavant par les opposants et les réticents à la vaccination. Malgré les progrès scientifiques importants dont nous avons été témoins, nous devons, en ce qui concerne l'acceptation de la vaccination et l'évaluation des risques, aller au-delà de la science et prendre en considération des forces sociales et politiques de plus grande portée.

Bien que Darwin n'ait pas cité Jenner et ses travaux sur la vaccination, Pasteur (1822-1895) l'a fait lorsqu'il a commencé à publier ses résultats sur ses premiers vaccins administrés à la volaille, en 1878-80 (Pichot, 1999). Louis Pasteur et Élie Metchnikoff (1845-1916), à Paris, Robert Koch (1843-1910), à Berlin, Martinus Beijerinck (1851-1931), à Delft, et Sergei Winogradsky (1856-1953), à Paris et Saint-Pétersbourg, ont établi les bases de la nouvelle science que l'on

20. Un bon exemple est celui du vaccin contre la grippe, qui doit être élaboré chaque année en fonction des souches dominantes apparues en Asie. L'évolution du virus de la grippe dans différents hôtes (oiseaux, humains, porcs, etc.) rend impossible l'éradication de cette maladie par un vaccin. Depuis le début des années 1990, les microbiologistes, se penchant sur l'évolution des maladies ayant déjà été, depuis un certain temps, contrôlées par des vaccins ou des antibiotiques, voient que les techniques médicales conventionnelles ne sont plus entièrement suffisantes. 
appellera la microbiologie et qui aura pour effet de transformer en profondeur le traitement des maladies infectieuses non seulement à l'échelle des personnes (médecine), mais aussi à celle des populations et des communautés (épidémiologie et santé publique). La microbiologie a joué un rôle de premier plan dans la validation des vaccins, a servi de base à leur expansion au-delà de la première découverte de Jenner sur la variole et a développé les connaissances nécessaires pour répondre à certaines questions posées par les opposants à la vaccination (Moulin, 1996; Madigan et coll., 2010). La microbiologie, se développant comme science à la fin du XIXe siècle grâce à Pasteur, à ses homologues ci-dessus mentionnés et à bien d'autres, a permis de dégager l'essentiel des données probantes faisant de la vaccination une méthode valide et sûre de contrôler les maladies infectieuses. Elle constitua également un moyen technique de concevoir de nouveaux vaccins contre une foule de maladies qui furent découvertes au même moment, en plus de proposer des méthodes destinées à assurer leur innocuité. Enfin, la microbiologie contenait les assises scientifiques d'une meilleure compréhension de l'immunologie et de la génétique, ce qui permit d'élaborer des critères d'exclusion pour les personnes présentant un risque potentiel accru.

Les travaux de Pasteur se démarquaient à cause de sa créativité dans la conception des expériences conçues pour faire progresser l'élaboration de vaccins pour les animaux et les hommes; on en a tiré une base expérimentale qui sert encore aujourd'hui. Par exemple, en mettant au point un vaccin contre le choléra des poules (Pichot, 1999), il exposa à la chaleur les bactéries infectieuses qu'il avait isolées, ce qui les a empêchées de se répliquer. On put alors inoculer ces bactéries inactivées dans les volailles sans les rendre malades, puisque les bactéries ne pouvaient se répliquer; celles-ci, demeurées entières, furent reconnues par le système immunitaire et les poules bénéficièrent donc d'une protection immunitaire prolongée. Ce fut là un des nombreux vaccins que Pasteur et son équipe mirent au point pour lutter contre les maladies des animaux. Ces vaccins devinrent des modèles et furent à la base de la conception des vaccins destinés aux humains. Grâce à ces travaux, on obtint un moyen 1) de produire de nouveaux vaccins en transformant les agents infectieux par un processus physique ou chimique et 2) de vérifier l'innocuité et l'efficacité des nouveaux vaccins, à l'aide de modèles animaux. Ces méthodes continuent de former la base de l'élaboration de nouveaux vaccins et médicaments. La méthode d'atténuation de la virulence des bactéries grâce à la chaleur, imaginée par Pasteur, fut adaptée à d'autres agents infectieux pour la création d'autres vaccins. Le premier vaccin contre la poliomyélite mis au point par Jonas Salk utilisait la formaldéhyde pour inactiver le virus (voir Naus, Law et Rinfret, au chapitre 9 du présent ouvrage) ${ }^{21}$.

Pasteur élabora un vaccin contre le virus de la rage en 1880 grâce à une série d'expériences utilisant les tissus cérébraux d'un enfant décédé de cette maladie (Pichot, 1999). Contrairement à Jenner et à son vaccin contre la vaccine, qui est une variante naturelle de la variole humaine, Pasteur a mis au point un vaccin contre le virus de la rage au cours de travaux de laboratoire complexes et non pas simplement en l'isolant dans un hôte différent. C'est pourquoi on dit de Pasteur qu'il fut le premier à concevoir un vaccin humain et non pas un vaccin dérivé de la variante naturelle d'une maladie. C'est une approche presque identique qui a inspiré Salk et de Sabin dans leur recherche d'un vaccin contre la poliomyélite, au cours des années 1950. Le processus de Pasteur se démarquait du fait qu'il se souciait fort peu de la barrière

21. Le vaccin antipoliomyélitique inactivé est celui qui est administré dans le calendrier normal d'immunisation des enfants au Canada et dans de nombreux autres pays. 
entre les espèces. Ayant été formé en génie chimique au moment où la chimie s'intéressait particulièrement à la compréhension des multiples transformations propres aux molécules organiques, Pasteur a fait des inoculations chez des lapins, des singes en bonne santé et des humains à partir de cerveaux et de moelles épinières de singes infectés par la rage, qu'il avait préparés après différentes modifications sous l'effet de la chaleur et de la dessiccation. Il utilisait des tissus infectés parce qu'il était incapable d'isoler l'agent infectieux de la rage ${ }^{22}$ et a poursuivi ses expériences comme s'il n'y avait pas de différence fondamentale entre un lapin, un singe et un homme ${ }^{23}$. Certains spécialistes contemporains de l'éthique auraient probablement mis en question la démarche pasteurienne, mais lui estimait que, dans son laboratoire, les lapins n'étaient que des véhicules commodes ou un moyen de mettre au point de nouveaux produits chimiques organiques afin de prévenir des maladies.

Dans l'élaboration d'un vaccin, il fallait aussi comprendre le phénomène de l'immunité, pour que le produit final soit sûr. Les travaux de Pasteur furent l'inspiration de ceux d'Élie Metchnikoff (1845-1916), qui s'intéressa à la phagocytose, volet fondamental de l'immunité à médiation cellulaire, qui explique pourquoi un vaccin peut engendrer une immunité durable (Conn et Conn, 1929). Cette théorie de l'immunité fait ressortir le rôle des globules blancs dans la réponse immunitaire aux agents infectieux comme les virus et les bactéries. Les vaccins sont efficaces parce que les globules blancs (les leucocytes et plus particulièrement les lymphocytes) sont en mesure de se nourrir à même les bactéries et virus, de sorte à produire l'immunité. Une compréhension croissante du système immunitaire est à l'origine de l'élaboration des vaccins modernes, qui luttent contre des maladies très communes, mais aussi très dangereuses; elle permet de poursuivre les recherches sur de nouveaux vaccins pour d'autres maladies.

La réduction du risque figurait parmi les grands objectifs du développement de la microbiologie appliquée à la vaccination. Offit (2005), se penchant sur le vaccin contre la poliomyélite, en dresse un excellent portrait. De nos jours, l'hésitation face à la vaccination est en grande partie attribuable à l'évaluation du risque, comme le démontrent Brunk (chapitre 3) et d'autres coauteurs. Cette notion est née au XVIII siècle, avec d'Alembert et Bernouilli, qui ont décrit les défis à surmonter en participant à la controverse sur l'inoculation de la variole (se reporter à la section "La variolation ou l'inoculation de la variole en Chine et en Europe ", ci-dessus). D'un côté, d'Alembert ([1821], 1967, 468) cite des opposants à l'inoculation et admet que les risques sont différents, selon qu'on opte pour l'inoculation ou pas:

"Car en supposant ... que le nombre de ceux qui périssent de la petite vérole soit quarante fois aussi grand que le nombre de ceux qui meurent de l'inoculation, s'ensuitil que les deux risques soient entre eux dans le même rapport? La nature de l'un et de l'autre est bien différente; quelque petit que l'on veuille supposer le risque de mourir de l'inoculation, celui qui se fait inoculer se soumet à courir ce risque dans un court espace de quinze jours, dans celui d'un mois tout au plus; au contraire, le risque de mourir de la petite vérole naturelle se répand sur tout le temps de la vie, et en devient tout autant plus petit pour chaque année et pour chaque mois ${ }^{24}$.»

22. À l'époque où travaillait Pasteur, on ne distinguait pas clairement les virus des bactéries - c'est André Lwoff, en 1957, qui fut le premier à les différencier.

23. Pasteur appliquait implicitement la théorie de la sélection naturelle en utilisant différentes espèces comme milieux distinctifs à partir desquels il produisait des variantes pouvant ensuite être mises à l'essai à titre de vaccins. Cela aurait été impossible à l'époque de Jenner et des spécialistes de l'histoire naturelle du siècle précédent, qui considéraient que les espèces étaient séparées par des barrières insurmontables.

24. Traduction du texte anglais par l'auteur

Histoire 
La microbiologie est une science qui permet d'établir avec de plus en plus de précision le risque associé à un vaccin en particulier. Dans le cas de la poliomyélite, on estime que le vaccin oral peut entraîner des effets indésirables graves chez un vacciné sur quatre millions. Ce risque, pour une population de l'envergure canadienne, est très faible et acceptable. Les bienfaits du vaccin sont donc supérieurs à ses risques. Malgré tout, les parents qui, par malchance, ont vu ces effets chez un enfant se préoccupent du risque, de quelque ampleur soit-il et il faut les comprendre. C'est une des raisons pour lesquelles le Canada utilise un vaccin antipoliomyélitique inactivé. Poursuivant son raisonnement, d'Alembert ([1821], 1967, 480) soulevait déjà la différence, en matière d'évaluation du risque, pour l'État et les parents:

"On a trop confondu l'intérêt que l'État en général peut avoir à l'inoculation, avec celui que les particuliers y peuvent trouver; ces deux intérêts peuvent être fort différents. Par exemple dans l'hypothèse que nous venons de faire, il est certain que l'État gagnerait à l'inoculation, puisqu'en sacrifiant un citoyen sur cinq, la société serait assurée de conserver ses autres membres sains et vigoureux jusqu'à l'âge de cent ans; cependant nous venons de voir que dans cette hypothèse, il n'y aurait pas de citoyens assez courageux ou assez téméraires, pour s'exposer à une opération, où il risquerait un contre quatre de perdre la vie ${ }^{25}$. »

La différence entre l'État et le citoyen peut expliquer en partie la réticence à la vaccination, dans un contexte où la prévalence des maladies infectieuses a été grandement réduite grâce à la vaccination, aux antibiotiques et à l'hygiène en général.

Aujourd'hui, des facteurs politiques compliquent souvent la perception qu'a le public de la vaccination. La campagne de vaccination antivariolique qui a eu lieu en 2003 aux ÉtatsUnis, en est un bon exemple. S'adressant au personnel médical et militaire, elle fut lancée par un décret du président George W. Bush. Plusieurs leaders politiques américains craignaient alors que des terroristes s'attaquent à l'armée et assurent ainsi la propagation de la variole. La plupart de l'effectif militaire visé au premier stade (97 p. cent) s'est conformé au décret, mais l'essentiel du personnel médical (moins de 10 p. cent) a refusé la vaccination. II apparut clairement alors que le risque d'une épidémie provoquée par une attaque biologique était négligeable, comparativement aux effets indésirables potentiels du vaccin ${ }^{26}$. Des campagnes aussi mal conçues et exécutées peuvent fort bien accroître la réticence à la vaccination dans la population en général.

\section{Conclusion}

La science compte généralement sur l'observation, la mesure et les données expérimentales pour, de là, construire un modèle de la réalité. II arrive parfois que la complexité et l'ambiguïté des données empêchent l'obtention d'un consensus sur un modèle donné. Dans ce contexte, les réticents d'aujourd'hui ne sont pas si différents des gens à qui l'on a présenté l'inoculation ou la vaccination il y a deux cents ans, malgré les formidables progrès de la microbiologie. Le vaccin antivariolique était une nouveauté au XIXe siècle et la population en avait peur. Aujourd'hui, il se trouve encore des gens qui ont peur des nouveaux vaccins conçus pour prévenir la rougeole, les oreillons, la rubéole, la grippe et le virus du papillome humain (VPH).

25. Traduction du texte anglais par l'auteur

26. MacKenzie (2003)

Histoire 
Si quelques-uns d'entre eux (rougeole, oreillons, rubéole) sont soutenus par un consensus scientifique élargi, d'autres (grippe, VPH) font encore l'objet de discussions au sein même des milieux scientifiques. On peut donc dire que le phénomène de réticence et d'opposition à la vaccination n'a rien de nouveau. On l'a rencontré à toutes les époques et à différents degrés, au XVIII e siècle où l'on pratiquait l'inoculation en Chine et en Europe, au début du $X I X{ }^{e}$ siècle quand on a conçu le vaccin antivariolique et au XXe siècle où l'on a mis au point de nouveaux vaccins pour prévenir les maladies causées par d'autres agents infectieux. L'hésitation face à la vaccination peut avoir eu des effets positifs, car elle a été à l'origine d'une bonne partie des travaux de recherche dans ce domaine. La science a maintenant donné la réponse à bon nombre des questions posées par les réticents. Malheureusement, celles qui demeurent aujourd'hui sont souvent basées sur une information douteuse sans fondement scientifique ou sur des convictions qu'une approche scientifique ne peut altérer. La réticence et l'opposition conservent cependant leurs conséquences réelles, c'est-à-dire les éclosions de maladies.

Ce chapitre doit nous rappeler que, dans une perspective historique, la réticence à la vaccination qui s'appuie sur des inquiétudes scientifiquement démontrables ouvre potentiellement la voie à l'innovation. Même si, à l'heure actuelle, la quasi-totalité des interrogations et des intrigues liées à la vaccination n'est pas fondée, l'histoire démontre que la réticence pourrait se poursuivre, poussant ainsi les scientifiques à ne pas oublier les inquiétudes que suscitent tous les volets de la vaccination et à demeurer constamment vigilants dans leur approche, relativement aux conséquences inattendues des projets de recherche sur les vaccins et des programmes de santé publique fondés sur la vaccination.

Ce bref aperçu des origines de la vaccination et des facteurs historiques agissant sur le phénomène de la réticence à la vaccination devrait mettre en lumière la nécessité de mieux comprendre l'histoire naturelle des virus et des vaccins et leur interaction avec les populations humaines, ainsi que les environnements socioculturels dans le cadre desquels on interprète ces derniers.

Je remercie Laurence Monnais, qui m'a fait part de ses opinions et suggestions pour la rédaction du présent chapitre. 


\section{Bibliographie}

Barquet, N., and P. Domingo. 1997. "Smallpox: The Triumph over the Most Terrible of the Ministers of Death." Annals of Internal Medicine 127: 635-42. http://dx.doi. org/10.7326/0003-4819-127-8_Part_1199710150-00010.

Basrur, S.V. 2005. Building the Foundation of a Strong Public Health System for Ontarians: Annual Report of the Chief Medical Officer of Health to the Ontario Legislative Assembly. Toronto: Ministry of Health and Long-Term Care.

Baxby, D. 1981. Jenner's Smallpox Vaccine: The Riddle of Vaccinia Virus and Its Origin. London: Heinemann Educational Books.

Conn, H.W., and H.J. Conn. 1929. Bacteriology. $4^{\text {th }}$ ed. Baltimore, MD: Williams and Wilkins Company.

D'Alembert, J. [1821] 1967. Réflexions sur l'inoculation. Vol. 1 of Euvres complètes de D'Alembert. Geneva: Slatkine.

Darwin, C. [1859] 2006. The Origin of Species. In From So Simple a Beginning: The Four Great Books of Charles Darwin, C. Darwin (author) and E.O. Wilson (editor), 1706 p. New York: Norton.

Diderot, D., and J. D'Alembert, eds. 1778. Encyclopédie: ou, Dictionnaire raisonné des sciences, des arts et des métiers / par une société de gens de lettres; mis en ordre \& publié par m. Diderot; \& quant à la partie mathématique, par m. d'Alembert. 36 vols. Geneva: Pellet.

Durbach, Nadja. 2005. Bodily Matters: The Anti-Vaccination Movement in England 1853-7907. Durham, NC: Duke University Press.

Fichman, M., and J. Keelan. 2007. "Resister's Logic: The Anti-Vaccination Arguments of Alfred Russel Wallace and Their Role in the Debates over Compulsory Vaccination in England, 1870-1907." Studies in History \& Philosophy of Biological and Biomedical Sciences 38 (3): 585-607. http://dx.doi.org/10.1016/j. shpsc.2007.06.006.

Guay, M., E. Cadieux, J. Désilets, P. Clément, C. Vanier, S. Briand, J. Lemaire, C. Michaud, E. Dubé, C. Boulet, n. Boulianne, and M. Landry. 2015. Quel est le meilleur mode d'organisation de la vaccination des enfants de 0-5 ans au Québec? Enquête auprès des parents. Quebec: Institut national de santé publique du Québec.

Jenner, E. [1798] 1966. An Inquiry into the Causes and Effects of the Variolae Vaccinae, a Disease Discovered in Some of the Western Counties of England, Particularly Gloucestershire and Known by the Name of Cow Pox. 75. Facsimile reprint. London: Dawsons of Pall Mall.

Khan, A.S., and G.L. Smith. 2010. Scientific Review of Variola Virus Research, 1999- 2010. Geneva: World Health organization.

Leung, A.K.C. 2011. "Variolation' and Vaccination in Late Imperial China, ca. 1570-1911." In History of Vaccine Development, ed. S.A. Plotkin, 5-12. New York: Springer. http://dx.doi.org/10.1007/978-1-4419-1339-5_2.

MacKenzie, D. 2003. "US Smallpox Vaccination Plan Grinds to a Halt." New Scientist, 22 August. http:// www.newscientist.com/article/dn4074-us-smallpox-vaccination- plan-grinds-to-a-halt. html\#. VTyMTydZqfQ.

Madigan, M.T., J.M. Martinko, D. Stahl, and P. Clark. 2010. Brock's Biology of Microorganisms. 13"th ed. San Francisco: Benjamin Cummings.

Moulin, Anne-Marie. 1996. L'Aventure de la vaccination. Paris: Fayard.

Needham, J., L. Gwei-djen, and N. Sivin. 2000. Biology and Biological Technology, Part 6, Medicine. Vol. 6 of Science and Civilisation in China. Cambridge: Cambridge University Press. 
Offit, P. 2005. "The Cutter Incident, 50 Years Later." New England Journal of Medicine 352 (14): 1411-2. http://dx.doi.org/10.1056/nEJMp048180.

Omer, S.B., W.K. Pan, N.A. Halsey, S. Stokley, L.H. Moulton, A.M. Navar, M. Pierce, and D.A. Salmon. 2006. "Nonmedical Exemptions to School Immunization Requirements: Secular Trends and Association of State Policies with Pertussis Incidence." Journal of the American Medical Association 296 (14): 1757-63. http://dx.doi.org/10.1001/jama.296.14.1757.

Omer, S.B., D.A. Salmon, W.A. Orenstein, M.P. deHart, and N. Halsey. 2009. "Vaccine Refusal, Mandatory Immunization, and the Risks of Vaccine-Preventable Diseases." New England Journal of Medicine 360 (19): 1981-8. http://dx.doi.org/10.1056/nEJMsa0806477.

Pichot, André, ed. 1999. Pasteur. Écrits scientifiques et médicaux. Paris: Garnier- Flammarion.

Sibbald, B. 2005. "Rubella Outbreak." Canadian Medical Association Journal 172: 1673.

Taurand, S. 1993. "Une expérience de presse au XVIIIe siècle: les Mémoires de Trévoux (1701-1762)." Revue francaise d'histoire du livre 62: 271-98.

Thucydides. 1928. History of the Peloponnesian War. Translated by C.F. Smith. Vol. 1. Loeb Classical Library. Cambridge, MA: Harvard University Press.

Vissière, I., and J.-L. Vissière, eds. 1979. Lettres édifiantes et curieuses de Chine par des missionaries jésuites 7702-7776. Paris: Garnier-Flammarion.

Wallace, A.R. 1898. The Wonderful Century: Its Successes and Its Failures. London: Swan Sonnenschein \& Co. http://dx.doi.org/10.5962/bhl.title.39656.

Weber, T.P. 2010. "Alfred Russel Wallace and the Antivaccination Movement in Victorian England." Emerging Infectious Diseases 16 (4): 664-8. http://dx.doi.org/10.3201/eid1604.090434. 